\title{
Estudo do efeito da amiodarona sobre o peso corpóreo e sobre determinantes morfológicos e citopatológicos do pulmão em ratos machos e fêmeas das linhagens Wistar, Wistar-Kyoto e SHR*
}

\author{
Thais Thomaz Queluz ${ }^{1}$, Maria Helena de Castro E Silva ${ }^{2}$, Silméia Garcia Zanatti ${ }^{3}$, \\ FREDERICO SOBRAL DE OliveIRA ${ }^{3}$, RODRIGo BAZAN ${ }^{3}$, JÚlio DEFAVERI ${ }^{4}$
}

Introdução: A maioria dos estudos experimentais sobre a toxicidade pulmonar induzida por amiodarona tem sido realizada em ratos machos da linhagem Fischer-344. Objetivos: Investigar o efeito da amiodarona sobre o peso corpóreo e sobre determinantes morfológicos e citopatológicos do pulmão em outras linhagens de ratos de ambos os sexos. Métodos: Grupos de ratos machos e de fêmeas das linhagens Wistar, Wistar-Kyoto (WKY) e espontaneamente hipertenso (SHR) receberam, por gavagem, durante quatro semanas, $175 \mathrm{mg} / \mathrm{kg} /$ dia de amiodarona em suspensão salina. Os grupos controles receberam apenas salina. Foram estudados ganho de peso corpóreo, celularidade total $e$ diferencial do lavado broncoalveolar (LBA) e histopatologia dos pulmões. Resultados: Mortalidade

pela amiodarona foi observada nos ratos WKY tratados, sendo maior em machos. Animais SHR tratados de ambos os sexos apresentaram o menor ganho de peso entre as linhagens estudadas. Ratos

machos Wistar e SHR tratados apresentaram maior ganho de peso do que as fêmeas das suas respectivas linhagens. O LBA de ratos SHR tratados de ambos os sexos era hemorrágico. A celularidade do LBA foi maior em machos tratados (WKY > Wistar > SHR). Entretanto, nos machos e fêmeas WKY a contagem diferencial mostrou o menor percentual de macrófagos e o maior de neutrófilos entre as três linhagens. Macrófagos do LBA de ratos Wistar tratados apresentavam fosfolipidose, enquanto a maioria dos macrófagos de ratos SHR tratados eram normais. No exame anatomopatológico dos pulmões, não houve diferenças entre os sexos e não foi observada pneumonite. Em ratos Wistar o exame foi caracterizado pela acentuada quantidade de macrófagos "espumosos" intra-alveolares, em ratos WKY, por inúmeros abscessos intraparenquimatosos e em ratos SHR, pela hemorragia alveolar.

Conclusões: 1) a amiodarona induz em ratos Wistar maior quantidade de macrófagos espumosos do que nas linhagens WKY e SHR, embora no modelo utilizado eles não desenvolvam pneumonite; 2) a amiodarona tem maior efeito sobre os determinantes morfológicos e citopatológicos do pulmão em animais do sexo masculino. (J Pneumol 2002;28(6):309-16)

\section{Study on the effect of amiodarone on the body weight and on lung morphologic and cytopathologic parameters of male and female Wistar, Wistar-Kyoto, and SHR rats}

Introduction: Most of the experimental studies on amiodarone-induced pulmonary toxicity have
been performed in male Fischer-344 rats. Objective: To investigate the effect of amiodarone on
body weight and on lung morphological and cytopathologic parameters in both genders of other
rat strains. Methods: Groups of male and female Wistar, Wistar-Kyoto (WKY) and spontaneously
hypertensive (SHR) rats received, $175 \mathrm{mg} / \mathrm{kg} /$ day of amiodarone suspended in saline by gavage for
four weeks. Controls received saline alone. Body weight gain, total cellularity, and differential of
the bronchoalveolar lavage (BAL) and lung histopathology were studied. Results: Mortality due to

* Trabalho realizado na Faculdade de Medicina de Botucatu - Unesp, SP

1. Professora Livre-Docente do Departamento de Clínica Médica. Chefe da Disciplina de Pneumologia.

2. Doutora pela FMB-Unesp. Professora Adjunta da Disciplina de Pneumologia da Faculdade de Medicina da Universidade Federal do Triângulo Mineiro.

3. Aluno de graduação.
4. Professor Livre-Docente do Departamento de Patologia.

Endereço para correspondência - Profa Dra Thais Helena Abrahão Thomaz Queluz, Departamento de Clínica Médica, Faculdade de Medicina de Botucatu - Unesp - 18618-000 - Botucatu, SP. Fax (14) 68222238; e-mail: queluz@fmb.unesp.br

Recebido para publicação em 20/4/02. Aprovado, após revisão, em 8/10/02. 
amiodarone was observed in treated WKY rats, mostly in males. Treated male and female SHR animals had less body weight gain among all strains studied. Male Wistar and SHR treated rats presented more body weight gain than females of the respective strains. BAL of treated SHR rats were hemorrhagic. BAL cellularity was higher in treated males (WKY > Wistar $>$ SHR). In WKY males and females, however, the differential count showed a lesser percent of macrophages and higher

of neutrophils than in the other strains. BAL macrophages of treated Wistar rats presented

phospholipidosis, whereas most macrophages of treated SHR rats were normal. In lung anatomicopathologic examination, no difference was found related to gender and no pneumonitis was observed. In Wistar rats, the examination was characterized by a marked quantity of intraalveolar "foamy" macrophages, numerous intraparenchymal abscesses were found in WKY rats, and alveolar hemorrhage was present in SHR rats. Conclusions: 1) amiodarone induces more foamy macrophages in Wistar rats than in the WKY and SHR strains, although they do not develop pneumonitis in the model used; 2) amiodarone has greater effect on lung morphological and cytopathologic parameters of male rats.

Descritores - Amiodarona. Fosfolipidose. Pneumonite droga-induzida. Pneumonite experimental.

Key words - Amiodarone. Drug-induced pneumonitis. Experimental pneumonitis. Phospholipidosis.

\section{INTRODUÇÃO}

Amiodarona é um derivado benzofurano iodado do grupo farmacológico das drogas anfifílicas catiônicas descrito, em 1960, como vasodilatador coronariano ${ }^{(1)}$ e usado, desde 1985, no tratamento das taquiarritmias ventriculares $^{(2,3)}$. Embora seja um anti-arrítmico efetivo, provoca diversos efeitos colaterais em 60 a $93 \%$ dos indivíduos que fazem uso da droga, tais como depósitos corneanos secundários à pigmentação do epitélio, alterações tireoidianas e hepáticas, insuficiência cardíaca, bradicardia, neurotoxicidade e fibrose pulmonar ${ }^{(2-6)}$. Desses, o mais sério é a toxicidade pulmonar, caracterizada por pneumonite intersticial - que ocorre em 5 a $7 \%$ dos indivíduos tratados com amiodarona - e que, em geral, evolui para fibrose pulmonar ${ }^{(5-9)}$. Acomete predominantemente indivíduos do sexo masculino com mais de $50 \operatorname{anos}^{(5,8)}$ e sua mortalidade está estimada em torno de 5 a $10 \%$ dos ca$\operatorname{sos}^{(2,6)}$.

A amiodarona, assim como outras drogas anfifílicas catiônicas, induz fosfolipidose em células de diversos tecidos ${ }^{(3,6,10-13)}$ : células pulmonares, hepáticas, células de Schwann, células endoteliais, pele, córnea e leucócitos periféricos. Esse fenômeno - indicativo de distúrbio no catabolismo intracelular de fosfolípides - manifesta-se morfologicamente pela presença de inclusões lamelares ricas em gordura.

$\mathrm{Na}$ toxicidade pulmonar induzida por amiodarona o aspecto proeminente é o desenvolvimento de fosfolipidose em vários tipos de células, como macrófagos alveolares, células endoteliais, células epiteliais tipo II, células intersticiais e fibroblastos ${ }^{(3,7,10-15)}$. Vários estudos descrevem aumento da celularidade do lavado broncoalveolar
Siglas e abreviaturas utilizadas neste trabalho

HE - Hematoxilina-eosina

LBA - Lavado broncoalveolar

PNM - Polimorfonuclear

SHR - Spontaneously hipertensive rat

WKY - Wistar-Kyoto

(LBA), mas os resultados são conflitantes sobre a contagem diferencial de células, havendo relatos de predomínio de macrófagos, de linfócitos e de neutrófilos ${ }^{(16-23)}$. Em geral, macrófagos alveolares de pacientes e de animais tratados com amiodarona, independentemente do desenvolvimento ou não da pneumonite, apresentam fosfolipidose, sendo denominados macrófagos "espumosos" (5-8, 11,13,14,17).

A literatura mostra que a suscetibilidade à amiodarona varia entre diferentes linhagens de ratos. Ratos Fischer344 desenvolvem inflamação pulmonar com doses relativamente pequenas do fármaco por tempo de administração curto ${ }^{(10-12)}$. Em ratos da linhagem Wistar, Wilson et al. ${ }^{(12)}$ não conseguiram induzir pneumonite com a droga e não observaram alterações significativas na celularidade do LBA. Por outro lado, Carvalho et al. ${ }^{(24)}$ induziram, em ratos Wistar, processo inflamatório pulmonar utilizando amiodarona por via oral em doses pequenas $e$ por tempo prolongado (três meses). Nesse estudo, observaram também que, com poucas semanas de uso da droga, os macrófagos alveolares apresentam alterações ultra-estruturais que precedem as lesões teciduais, as quais são caracterizadas por áreas focais de infiltrado de linfócitos, plasmócitos e macrófagos, diferentes do padrão intersticial difuso, espessamento de septos alveolares relatado em outras linhagens de ratos e em humanos.

Considerando que a suscetibilidade à amiodarona varia em diferentes linhagens de ratos, que humanos do sexo masculino são mais suscetíveis à droga do que os do sexo feminino e que os estudos sobre a celularidade do LBA na toxicidade por amiodarona, em humanos e em animais 
de experimentação, mostram resultados variáveis, o objetivo do presente trabalho foi avaliar o efeito da amiodarona sobre o peso corpóreo e sobre determinantes morfológicos e citopatológicos do pulmão em ratos machos e fêmeas das linhagens Wistar, Wistar-Kyoto (WKY) e espontaneamente hipertenso (SHR).

\section{MATERIAl E MÉTOdOS}

Delineamento experimental - Foram utilizados 40 ratos de cada uma das linhagens Wistar, WKY e SHR, com idade entre oito e 10 semanas. Todos os animais eram procedentes do Biotério Central do Campus de Botucatu da Unesp, alojados em caixas para 10 animais no Biotério do Laboratório Experimental do Departamento de Clínica Médica, e receberam dieta apropriada e água ad libitum.

Esquema de estudo de cada linhagem:

G1 - 10 ratos machos tratados com amiodarona por quatro semanas.

G2 - 10 ratos machos tratados com salina por quatro semanas.

G3 - 10 ratos fêmeas tratados com amiodarona por quatro semanas.

G4 - 10 ratos fêmeas tratados com salina por quatro semanas.

Os animais dos grupos tratados com amiodarona receberam $175 \mathrm{mg} / \mathrm{kg} / \mathrm{dia}$ de cloridrato de amiodarona (Ancoron - Libbs) diluído em $2 \mathrm{ml}$ de solução salina, por gavagem, cinco dias por semana. Os animais dos grupos controles receberam o mesmo volume de solução salina.

O sacrifício foi feito com éter sulfúrico, sendo realizados esternotomia e exposição da traquéia e dos pulmões $e$ LBA in situ. Em seguida, os pulmões foram retirados em bloco e fixados em formalina a $10 \%$ por 24 horas, incluídos em parafina, cortados na espessura de $5 \mu \mathrm{m} e$ corados pela hematoxilina-eosina (HE).

Os pesos dos animais foram registrados diariamente, sendo calculado, ao término do estudo, o diferencial de peso (peso final - peso inicial).

Técnica do $\mathbf{L B A}$ - A traquéia foi canulada e $3 \mathrm{ml}$ de solução salina tamponada (PBS) estéril foi instilada e aspirada dos pulmões, com uso de seringa, por cinco vezes. Este procedimento foi feito por três vezes massageandose gentilmente os pulmões, recuperando-se um volume de aproximadamente $8 \mathrm{ml}$.

Contagem do número total e do diferencial de células presentes no LBA - O número total de células foi determinado adicionando-se $10 \mu$ l de solução cristal violeta a $0,5 \%$ em ácido acético glacial a $30 \%$ a $90 \mu \mathrm{l}$ de suspensão celular. A contagem foi realizada em câmara hemocitométrica de Neubauer e os resultados expressos em número absoluto de células. Para contagem diferen- cial, a suspensão celular do LBA foi ajustada para a concentração de 1 x $10^{6}$ células $/ \mathrm{ml}$ e $200 \mu \mathrm{l}$ foram centrifugados por cinco minutos a $1.500 \mathrm{rpm}$. Em seguida, a lâmina foi removida, fixada em acetona por 12 horas e corada pelo método do Shorr. O percentual de macrófagos, linfócitos e polimorfonucleados (PMN) foi determinado contando-se 200 células com objetiva de aumento 100x.

Exame histopatológico dos pulmões - As lâminas coradas por HE foram examinadas quanto ao padrão (focal ou difuso) e o tipo de celularidade do infiltrado inflamatório intersticial. A presença de macrófagos alveolares "espumosos" intra-alveolares foi quantificada, de acordo com a extensão de alvéolos comprometidos, de $1+$ a $4+$. A interpretação foi realizada sem que o examinador tivesse conhecimento do grupo ao qual pertencia o material examinado.

Análise estatística - Foi realizada a análise da variância do esquema fatorial $2 \times 2 \times 3$ (sexo, grupo e linhagem) no estudo inteiramente casualizado, complementado com o teste de comparações múltiplas de Tukey ${ }^{(25)}$. Os resultados dos testes foram expressos em letras maiúsculas e minúsculas, mostrando significância estatística quando estas letras não são coincidentes. As estatísticas calculadas foram consideradas significativas quando $p<0,05$.

\section{Resultados}

A média e o desvio padrão da variáveis estudadas conforme linhagem, grupo de tratamento e sexo estão expressos na Tabela 1. As médias e os resultados do teste estatístico das comparações linhagem e sexo nos grupos controles, linhagem e sexo nos grupos tratados, linhagem e grupo nos machos, linhagem e grupo nas fêmeas estão expressos, respectivamente, nas Tabelas 2 a 5 .

\section{Mortalidade, peso corporal, celularidade total e diferencial do LBA e exame anatomopatológico dos pulmões nas diferentes linhagens}

Linhagem Wistar - Nenhum rato desta linhagem morreu durante o experimento. Os machos tratados e controles apresentaram diferencial de peso significativamente maior que as fêmeas tratadas e controles, respectivamente; o diferencial de peso foi significativamente menor nos animais tratados de ambos os sexos em relação aos controles. Os machos tratados apresentaram maior número de células no LBA que as fêmeas tratadas e que os machos controles. A contagem diferencial de células mostrou predomínio acentuado de macrófagos (a maioria "espumosos"), poucos linfócitos e raros PMN, não havendo diferença significante entre os grupos ou entre os sexos. Os exames anatomopatológicos dos pulmões de machos $e$ fêmeas tratados revelaram grande quantidade de macró- 
TABELA 1

Média \pm desvio padrão das variáveis estudadas conforme linhagem, grupo de tratamento e sexo

\begin{tabular}{|c|c|c|c|c|c|c|c|}
\hline \multirow[t]{2}{*}{ Linhagem } & \multirow[t]{2}{*}{ Grupo } & \multirow[t]{2}{*}{ Sexo } & \multicolumn{5}{|c|}{ Variável } \\
\hline & & & Dif. peso (g) & LBA $\left(X 10^{6}\right)$ & MA (\%) & Linf. (\%) & PMN (\%) \\
\hline \multirow[t]{4}{*}{ W istar } & Controle & $M$ & $118,00 \pm 14,23$ & $17,32 \pm 4,39$ & $96,00 \pm 2,35$ & $3,10 \pm 1,59$ & $0,90 \pm 1,37$ \\
\hline & & $\mathrm{F}$ & $77,60 \pm 6,75$ & $19,61 \pm 8,27$ & $96,20 \pm 2,09$ & $3,50 \pm 2,22$ & $0,30 \pm 0,67$ \\
\hline & Tratado & M & $103,00 \pm 19,89$ & $29,60 \pm 4,48$ & $95,40 \pm 2,22$ & $2,40 \pm 1,26$ & $2,20 \pm 2,04$ \\
\hline & & $\mathrm{F}$ & $50,10 \pm 3,66$ & $19,93 \pm 8,90$ & $97,30 \pm 2,11$ & $2,00 \pm 1,33$ & $0,70 \pm 0,94$ \\
\hline \multirow[t]{4}{*}{ W KY } & Controle & $M$ & $75,80 \pm 5,11$ & $18,54 \pm 4,65$ & $96,90 \pm 2,51$ & $2,40 \pm 1,83$ & $0,70 \pm 1,33$ \\
\hline & & $\mathrm{F}$ & $69,90 \pm 6,47$ & $15,93 \pm 2,55$ & $97,70 \pm 2,16$ & $1,80 \pm 1,54$ & $0,50 \pm 0,97$ \\
\hline & Tratado & $M$ & $65,87 \pm 7,19$ & $56,27 \pm 10,06$ & $63,62 \pm 16,74$ & $11,50 \pm 8,15$ & $24,87 \pm 11,03$ \\
\hline & & $\mathrm{F}$ & $58,22 \pm 3,59$ & $54,88 \pm 17,06$ & $67,44 \pm 10,60$ & $4,33 \pm 5,12$ & $28,22 \pm 8,70$ \\
\hline \multirow[t]{4}{*}{ SHR } & Controle & M & $60,00 \pm 9,80$ & $12,51 \pm 3,79$ & $97,20 \pm 1,98$ & $2,10 \pm 1,19$ & $0,70 \pm 0,94$ \\
\hline & & $\mathrm{F}$ & $29,20 \pm 2,44$ & $12,48 \pm 6,05$ & $94,70 \pm 2,40$ & $4,70 \pm 2,21$ & $0,60 \pm 1,07$ \\
\hline & Tratado & $M$ & $35,30 \pm 16,76$ & $20,12 \pm 7,09$ & $97,70 \pm 2,62$ & $2,30 \pm 2,62$ & $0,00 \pm 0,00$ \\
\hline & & $\mathrm{F}$ & $11,50 \pm 84,20$ & $13,85 \pm 5,26$ & $97,20 \pm 2,52$ & $2,70 \pm 2,58$ & $0,10 \pm 0,31$ \\
\hline
\end{tabular}

Dif. peso, diferencial de peso; F, feminino; LBA, número de células do lavado broncoalveolar; Linf., linfócito; M, masculino; MA, macrófago; PMN, polimorfonuclear; SHR, spontaneously hypertensive rat; WKY, Wistar-Kyoto.

TABELA 2

Média e resultado do teste estatístico da comparação linhagem e sexo no grupo controle

\begin{tabular}{lcrrrrr}
\hline \multirow{2}{*}{ Linhagem } & Sexo & \multicolumn{5}{c}{ Variável } \\
\cline { 2 - 7 } & & Dif. peso (g) & LBA (X106) & MA (\%) & Linf. (\%) & PMN (\%) \\
\hline \multirow{2}{*}{ Wistar } & M & $118,00 \mathrm{bC}$ & $17,32 \mathrm{aA}$ & $96,00 \mathrm{aA}$ & $3,10 \mathrm{aA}$ & $0,90 \mathrm{aA}$ \\
& $\mathrm{F}$ & $77,60 \mathrm{aB}$ & $19,61 \mathrm{aA}$ & $96,20 \mathrm{aA}$ & $3,50 \mathrm{aA}$ & $0,30 \mathrm{aA}$ \\
\hline \multirow{2}{*}{ W KY } & $\mathrm{M}$ & $75,80 \mathrm{aB}$ & $18,54 \mathrm{aA}$ & $96,90 \mathrm{aA}$ & $2,40 \mathrm{aA}$ & $0,70 \mathrm{aA}$ \\
& $\mathrm{F}$ & $69,90 \mathrm{aB}$ & $15,93 \mathrm{aA}$ & $97,70 \mathrm{aA}$ & $1,80 \mathrm{aA}$ & $0,50 \mathrm{aA}$ \\
\hline \multirow{2}{*}{ SHR } & $\mathrm{M}$ & $60,00 \mathrm{bA}$ & $12,51 \mathrm{aA}$ & $97,20 \mathrm{aA}$ & $2,10 \mathrm{aA}$ & $0,70 \mathrm{aA}$ \\
& $\mathrm{F}$ & $29,20 \mathrm{aA}$ & $12,48 \mathrm{aA}$ & $94,70 \mathrm{aA}$ & $4,70 \mathrm{aA}$ & $0,60 \mathrm{aA}$ \\
\hline
\end{tabular}

Dif. peso, diferencial de peso; F, feminino; LBA, número de células do lavado broncoalveolar; Linf., linfócito; $M$, masculino; MA, macrófago; PM N, polimorfonuclear; SH R, spontaneously hypertensive rat; W KY, W istar-Kyoto.

Letras minúsculas $(a, b, c)=$ Comparação sexo/linhagem

Letras maiúsculas $(A, B, C)=$ Comparação linhagem/sexo

TABELA 3

Média e resultado do teste estatístico da comparação linhagem e sexo no grupo tratado

\begin{tabular}{|c|c|c|c|c|c|c|}
\hline \multirow[t]{2}{*}{ Linhagem } & \multirow[t]{2}{*}{ Sexo } & \multicolumn{5}{|c|}{ Variável } \\
\hline & & D if. peso (g) & LBA $\left(X 10^{6}\right)$ & MA (\%) & Linf. (\%) & PMN (\%) \\
\hline Wistar & $\begin{array}{l}M \\
F\end{array}$ & $\begin{array}{r}103,00 \mathrm{bC} \\
50,10 \mathrm{aB}\end{array}$ & $\begin{array}{l}29,60 \mathrm{bB} \\
19,93 \mathrm{aA}\end{array}$ & $\begin{array}{l}95,40 \mathrm{aB} \\
97,30 \mathrm{aB}\end{array}$ & $\begin{array}{l}2,40 \mathrm{aA} \\
2,00 \mathrm{aA}\end{array}$ & $\begin{array}{l}2,20 \mathrm{aA} \\
0,70 \mathrm{aA}\end{array}$ \\
\hline WKY & $\begin{array}{l}M \\
F\end{array}$ & $\begin{array}{l}65,87 \mathrm{aB} \\
58,22 \mathrm{aB}\end{array}$ & $\begin{array}{l}56,27 \mathrm{aC} \\
54,88 \mathrm{aB}\end{array}$ & $\begin{array}{l}63,62 \mathrm{aA} \\
67,44 \mathrm{aA}\end{array}$ & $\begin{array}{r}11,50 \mathrm{bB} \\
4,33 \mathrm{aA}\end{array}$ & $\begin{array}{l}24,88 \mathrm{aB} \\
28,22 \mathrm{aB}\end{array}$ \\
\hline SHR & $\begin{array}{l}M \\
F\end{array}$ & $\begin{array}{l}35,30 \mathrm{bA} \\
11,50 \mathrm{aA}\end{array}$ & $\begin{array}{l}20,12 \text { aA } \\
13,85 \text { aA }\end{array}$ & $\begin{array}{l}97,70 \mathrm{aB} \\
97,20 \mathrm{aB}\end{array}$ & $\begin{array}{l}2,30 \mathrm{aA} \\
2,70 \mathrm{aA}\end{array}$ & $\begin{array}{l}0,00 \mathrm{aA} \\
0,10 \mathrm{aA}\end{array}$ \\
\hline
\end{tabular}

Dif. peso, diferencial de peso; F, feminino; LBA, número de células do lavado broncoalveolar; Linf., linfócito; M, masculino; MA, macrófago; PM N, polimorfonuclear; SH R, spontaneously hypertensive rat; WKY, W istar-Kyoto.

Letras minúsculas $(a, b, c)=$ Comparação sexo/linhagem

Letras maiúsculas $(A, B, C)=$ Comparação linhagem/sexo 
TABELA 4

Média e resultado do teste estatístico da comparação linhagem e grupo nos machos

\begin{tabular}{lllllrr}
\hline \multirow{2}{*}{ Linhagem } & \multirow{6}{*}{ Grupo } & \multicolumn{5}{c}{ Variável } \\
\cline { 3 - 7 } & & Dif. peso (g) & LBA (X106) & MA (\%) & Linf. (\%) & PMN (\%) \\
\hline \multirow{2}{*}{ W istar } & Controle & $118,00 \mathrm{bC}$ & $17,32 \mathrm{aA}$ & $96,00 \mathrm{aA}$ & $3,10 \mathrm{aA}$ & $0,90 \mathrm{aA}$ \\
& Tratado & $103,00 \mathrm{aC}$ & $29,60 \mathrm{bB}$ & $95,40 \mathrm{aB}$ & $2,40 \mathrm{aA}$ & $2,20 \mathrm{aA}$ \\
\hline \multirow{2}{*}{ W KY } & Controle & $75,80 \mathrm{bB}$ & $18,54 \mathrm{aA}$ & $96,90 \mathrm{bA}$ & $2,40 \mathrm{aA}$ & $0,70 \mathrm{aA}$ \\
& Tratado & $65,87 \mathrm{aB}$ & $56,27 \mathrm{bC}$ & $63,62 \mathrm{aA}$ & $11,50 \mathrm{bB}$ & $24,88 \mathrm{bB}$ \\
\hline \multirow{2}{*}{ SHR } & Controle & $60,00 \mathrm{bA}$ & $12,51 \mathrm{aA}$ & $97,20 \mathrm{aA}$ & $2,10 \mathrm{aA}$ & $0,70 \mathrm{aA}$ \\
& Tratado & $35,30 \mathrm{aA}$ & $20,12 \mathrm{bA}$ & $97,70 \mathrm{aB}$ & $2,30 \mathrm{aA}$ & $0,00 \mathrm{aA}$ \\
\hline
\end{tabular}

Dif. peso, diferencial de peso; F, feminino; LBA, número de células do lavado broncoalveolar; Linf., linfócito; M, masculino; MA, macrófago; PM N, polimorfonuclear; SH R, spontaneously hypertensive rat; W KY, W istar-Kyoto.

Letras minúsculas $(a, b, c)=$ Comparação grupo/linhagem

Letras maiúsculas $(A, B, C)=$ Comparação linhagem/grupo

TABELA 5

Média e resultado do teste estatístico da comparação linhagem e grupo nas fêmeas

\begin{tabular}{llllllr}
\hline \multirow{2}{*}{ Linhagem } & Grupo & \multicolumn{5}{c}{ Variável } \\
\cline { 3 - 7 } & & Dif. peso (g) & LBA (X106) & MA (\%) & Linf. (\%) & PMN (\%) \\
\hline \multirow{2}{*}{ W istar } & Controle & $77,60 \mathrm{bB}$ & $19,61 \mathrm{aA}$ & $96,20 \mathrm{aA}$ & $3,50 \mathrm{aA}$ & $0,30 \mathrm{aA}$ \\
& Tratado & $50,10 \mathrm{aB}$ & $19,93 \mathrm{aA}$ & $97,30 \mathrm{aB}$ & $2,00 \mathrm{aA}$ & $0,70 \mathrm{aA}$ \\
\hline \multirow{2}{*}{ W KY } & Controle & $69,90 \mathrm{bB}$ & $15,93 \mathrm{aA}$ & $97,70 \mathrm{bA}$ & $1,80 \mathrm{aA}$ & $0,50 \mathrm{aA}$ \\
& Tratado & $58,22 \mathrm{aB}$ & $54,88 \mathrm{bB}$ & $67,44 \mathrm{aA}$ & $4,33 \mathrm{aA}$ & $28,22 \mathrm{bB}$ \\
\hline \multirow{2}{*}{ SHR } & Controle & $29,20 \mathrm{bA}$ & $12,48 \mathrm{aA}$ & $94,70 \mathrm{aA}$ & $4,70 \mathrm{aA}$ & $0,60 \mathrm{aA}$ \\
& Tratado & $11,50 \mathrm{aA}$ & $13,85 \mathrm{aA}$ & $97,20 \mathrm{aB}$ & $2,70 \mathrm{aA}$ & $0,10 \mathrm{aA}$ \\
\hline
\end{tabular}

Dif. peso, diferencial de peso; F, feminino; LBA, número de células do lavado broncoalveolar; Linf., linfócito; M , masculino; M A, macrófago; PM N, polimorfonuclear; SHR, spontaneously hypertensive rat; WKY, W istar-Kyoto.

Letras minúsculas $(a, b, c)=$ Comparação grupo/linhagem

Letras maiúsculas $(A, B, C)=$ Comparação linhagem/grupo

fagos "espumosos" intra-alveolares $(+3)$ e áreas de infiltrado linfoplasmocitário perivascular discreto. Os septos alveolares encontravam-se íntegros.

Linhagem WKY - Entre os animais dos grupos tratados a taxa de mortalidade foi de $20 \%$ entre os machos $(2 / 10)$ e de $10 \%$ entre as fêmeas (1/10). O diferencial de peso corpóreo foi menor nos ratos tratados de ambos os sexos em relação aos controles. Machos e fêmeas apresentaram maior número de células no LBA em relação aos seus respectivos controles. Além disso, esses animais apresentaram, em relação aos seus controles, menor quantidade de macrófagos, raramente "espumosos", e aumento significativo no percentual de PMN. Os machos tratados apresentaram, ainda, maior percentual de linfócitos no LBA que as fêmeas tratadas e que os machos controles. O exame anatomopatológico dos pulmões dos animais tratados, de ambos os sexos, revelou infiltrado linfoplasmocitário perivascular e peribrônquico moderado, com intenso infiltrado inflamatório neutrofílico alveolar e intersticial, além da formação de múltiplos abscessos pulmonares. A presença de macrófagos "espumosos" foi discreta, variando de $1+$ a $2+$.

Linhagem SHR - Nenhum rato desta linhagem morreu durante o experimento. $\mathrm{O}$ diferencial de peso dos machos tratados e controles foi maior em relação às fêmeas tratadas e controles, respectivamente. Os animais tratados, de ambos os sexos, apresentaram diferencial de peso menor que os animais dos grupos controles. Machos tratados apresentaram maior número de células no LBA que os machos do grupo controle. $\mathrm{Na}$ análise diferencial da população celular presente no LBA dos grupos tratados $e$ controles havia predomínio acentuado de macrófagos (raros "espumosos"), poucos linfócitos e raros PMN, sem diferença entre os sexos. Machos e fêmeas tratados apresentaram, ao exame anatomopatológico dos pulmões, hemorragia alveolar importante, com infiltrado inflama- 

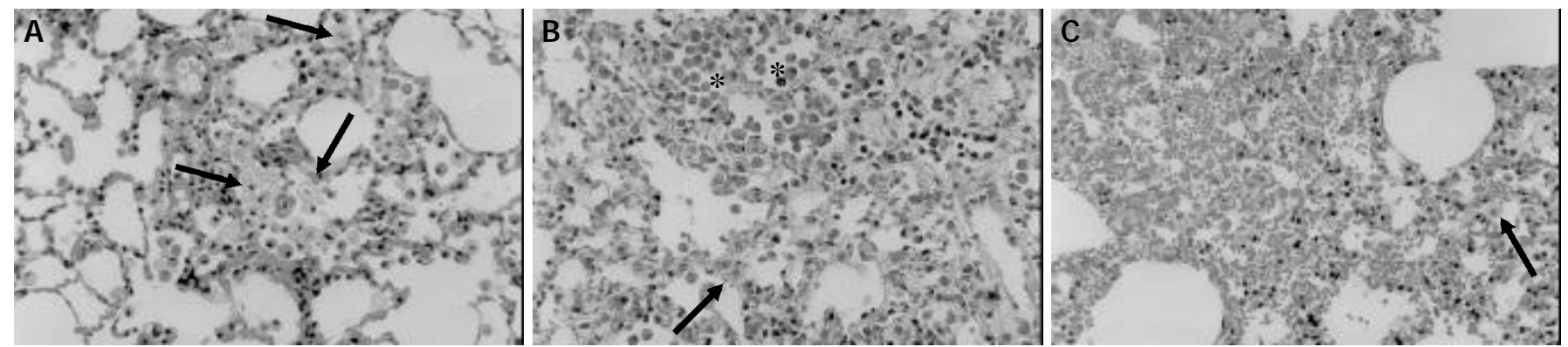

Figura 1 - Microscopia óptica de pulmão de rato tratado com amiodarona. A) Linhagem Wistar: numerosos macrófagos "espumosos" intraalveolares (setas). Hematoxilina-eosina x100. B) Linhagem WKY: infiltrado neutrofílico (cabeça de seta) e raros macrófagos "espumosos" (setas). Hematoxilina-eosina x40. C) Linhagem SHR: hemorragia alveolar intensa, colapso alveolar e raros macrófagos "espumosos" (setas). Hematoxilina-eosina $x 40$.
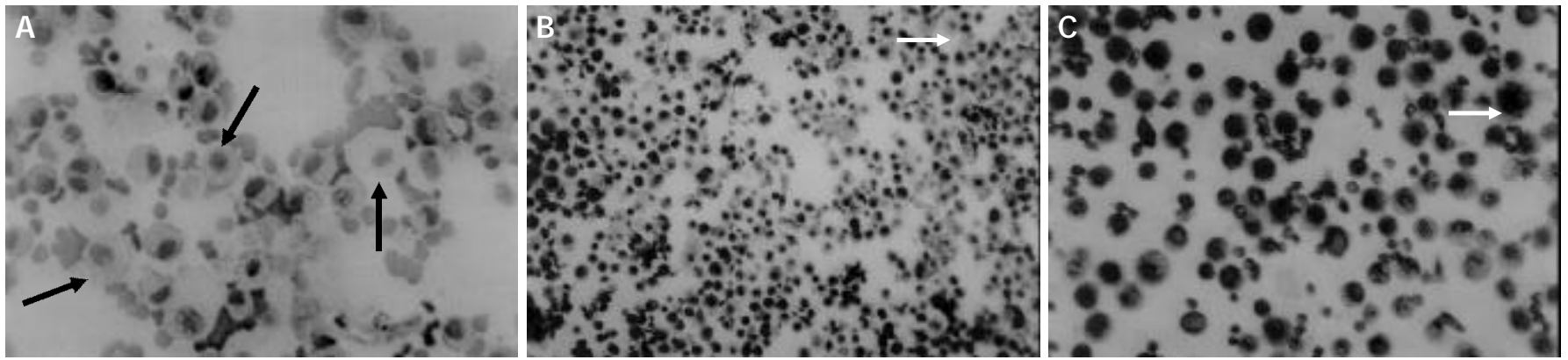

Figura 2 - Microscopia óptica de lavado bronco-alveolar de rato tratado com amiodarona. A) Linhagem Wistar: numerosos macrófagos "espumosos" (setas). Shorr x200. B) Linhagem WKY: celuridade aumentada com numerosos neutrófilos e macrófagos; raros macrófagos "espumosos" (setas). Shorr x100. C) Linhagem SHR: várias hemácias e raros macrófagos "espumosos" (setas). Shorr x200.

tório linfoplasmocitário perivascular discreto e poucos macrófagos alveolares "espumosos" intra-alveolares $(1+)$.

\section{Comparação das variáveis estudadas entre as li- nhagens SHR, WKY e Wistar}

Mortalidade pela amiodarona foi observada apenas nos grupos tratados da linhagem WKY, sendo maior no sexo masculino. Embora sem mortalidade, os animais SHR tratados de ambos os sexos apresentaram sangramento importante durante a realização do LBA ( $50 \%$ dos animais estudados).

Em relação ao peso corporal, animais SHR tratados de ambos os sexos apresentaram o menor diferencial de peso entre as linhagens estudadas. Ratos machos Wistar e SHR tratados apresentaram maior diferencial de peso do que as fêmeas das suas respectivas linhagens.

Os achados mais característicos do LBA nas linhagens estudadas estão ilustrados nas Figura 1 A, B, C. O maior número de células recuperadas no LBA foi observado em machos, sendo maior na linhagem WKY, seguida pela linhagem Wistar e, por último, pela linhagem SHR. Entretanto, nos machos e fêmeas WKY a contagem diferencial mostrou o menor percentual de macrófagos - poucos de- les "espumosos" - e o maior de PMN entre as três. A maioria dos macrófagos recuperados de LBA de ratos tratados da linhagem Wistar apresentava características morfológicas de fosfolipidose, enquanto estas características foram observadas poucas vezes em macrófagos de ratos SHR tratados.

Quanto ao exame anatomopatológico dos pulmões, não foram observadas diferenças entre os sexos. O exame dos ratos Wistar foi caracterizado pela acentuada quantidade de macrófagos "espumosos" intra-alveolares, dos ratos WKY pela presença de inúmeros abscessos intraparenquimatosos e dos ratos SHR pela hemorragia alveolar (Figura $2 \mathrm{~A}, \mathrm{~B}, \mathrm{C}$ ). Vários animais dos grupos controles das três linhagens apresentaram áreas focais de infiltrado linfoplasmocitário perivascular e peribrônquico discretos, que foram abstraídos nos exames dos grupos tratados.

\section{DISCUSSÃO}

A patogênese da pneumonite induzida pela amiodarona ainda é controversa, com três mecanismos básicos propostos: ação direta da droga sobre as células pulmonares, ação indireta através de mecanismos de hipersen- 
sibilidade e mecanismos oxidantes ${ }^{(10,26-32)}$. Muito desse conhecimento foi obtido em modelos experimentais, sendo um modelo clássico de pneumonite induzida por amiodarona o desenvolvido por Wilson et al. ${ }^{(19)}$ em ratos da linhagem Fischer-344. O racional para a realização do presente trabalho foi a procura, entre as linhagens disponíveis em nosso meio, de uma linhagem de ratos suscetível à amiodarona. Como em humanos a pneumonite por essa droga acomete principalmente indivíduos do sexo masculino, foram estudados animais de ambos os sexos. Dessa maneira, foi possível verificar-se diferenças entre as linhagens e entre sexos.

A linhagem Wistar é menos suscetível à amiodarona quando comparada com a linhagem Fischer-344(10,12). Entretanto, em ratos Wistar tratados com a droga têm sido descritas alterações na celularidade do LBA e presença de macrófagos alveolares "espumosos", semelhantes aos encontrados na linhagem Fischer-344 e em humanos tratados com a droga ${ }^{(10)}$. Pneumonite droga-induzida não tem sido observada em ratos Wistar ${ }^{(12)}$, exceto por Carvalho et al. ${ }^{(24)}$ após tempo prolongado de tratamento, porém, com características anatomopatológicas diferentes das observadas em pulmões de ratos Fischer-344 e de humanos portadores da doença.

Como a linhagem Wistar não é isogênica, estando, portanto, sujeita a variações individuais, decidimos testar a possibilidade de a amiodarona causar lesões pulmonares em ratos de outras linhagens isogênicas que não a Fischer344. Escolhemos a linhagem SHR porque esses animais, devido à hipertensão arterial, desenvolvem hipertrofia cardíaca e suas complicações, o que, de certa maneira, reproduz as situações clínicas nas quais a amiodarona é utilizada $^{(33)}$. Seu controle genético normotenso, a linhagem WKY, é altamente sensível a agressões de origem imunológica, sendo utilizada em modelos experimentais de lesões glomerulares e pulmonares por imunocomple$\operatorname{xos}^{(34)}$. Sobretudo, não há na literatura estudos sobre a ação da amiodarona em pulmões de ratos SHR e WKY.

A escolha da dose da droga foi baseada nos modelos experimentais de pneumonite por amiodarona em ratos Fischer-344, que induz aumento de celularidade do LBA $e$ aparecimento de fosfolipidose nos macrófagos alveolares já na $3{ }^{a}$ semana de tratamento ${ }^{(12,13)}$.

Os resultados do presente trabalho mostram que das três linhagens estudadas os animais da linhagem Wistar apresentaram maior suscetibilidade pulmonar à amiodarona. O LBA dos ratos Wistar tratados revelou aumento do número total de células e os típicos macrófagos alveolares "espumosos", descritos em humanos e em animais de experimentação ${ }^{(1,3,6,10,16,19)}$. Entretanto, não foi observada, à microscopia óptica, pneumonite droga-induzida. Provavelmente, a dose relativamente baixa de amiodaro- na e o período curto de estudo - diferentemente do trabalho de Carvalho et al. ${ }^{(24)}$ - foram responsáveis pela ausência de pneumonite. A contagem diferencial das células recuperadas no LBA revelou predomínio de macrófagos, achado semelhante ao encontrado por Wilson et al. ${ }^{(19)}$ em ratos Fischer-344.

Em ratos SHR, o LBA foi francamente hemorrágico, talvez pela fragilidade capilar secundária à hipertensão arterial somada à manipulação para realização do LBA. Outra explicação para esse achado seria maior toxicidade da amiodarona para as células endoteliais. Israel-Biet et al. ${ }^{(18)}$, que observavam maior sangramento no LBA de humanos na fase inicial da pneumonite por amiodarona, atribuem este fenômeno a uma possível ação tóxica da droga sobre as células endoteliais. A amiodarona não induziu o aparecimento significante de macrófagos "espumosos" nem de inflamação pulmonar intersticial nos ratos SHR de ambos os sexos, dados que sugerem que, nesse modelo experimental, a droga tem pouca ação pneumotóxica.

Em ratos WKY, a amiodarona provocou elevadas morbidade e mortalidade. Os animais apresentaram importante redução no ganho de peso corpóreo e acentuada suscetibilidade a infecções pulmonares. Não foram investigadas as causas desses achados, mas pode ser sugerido que: 1) nessa linhagem, muito sensível a agressões imunológicas, a droga altera mecanismos de defesa, permitindo infecções graves e perda de peso; 2) o metabolismo da amiodarona em animais dessa linhagem provoca alterações que levam à desnutrição com conseqüente suscetibilidade para infecções; 3) pode ter ocorrido a concomitância das duas hipóteses acima.

Nas três linhagens estudadas, o aumento de celularidade do LBA foi maior nos animais do sexo masculino. Rakita et al. ${ }^{(8)}$ chamaram atenção para o fato de a pneumonite por amiodarona em humanos acometer preferencialmente indivíduos do sexo masculino e Reasor et al. ${ }^{(11)}$ mostraram que os níveis de amiodarona no tecido pulmonar de fêmeas da linhagem Fischer-344 eram menores que no de machos. O motivo dessa diversidade entre os sexos não está determinado, sendo necessários estudos genéticos e/ou hormonais detalhados, que não foram objeto de estudos neste trabalho.

Também em relação ao ganho de peso corpóreo foram observadas diferenças entre os sexos nas linhagens estudadas. Embora as fêmeas controles tenham apresentado ganho de peso significativamente menor que os machos controles de suas respectivas linhagens, houve também diferença estatisticamente significante entre o diferencial de peso das fêmeas tratadas e seus respectivos controles, isto é, as fêmeas ganharam menos peso com o uso da droga do que os machos. Alterações de peso em ratos tratados com amiodarona têm sido relatadas na literatura e explicadas pelos efeitos da droga sobre o trato 
gastrointestinal e fígado e/ou pela indução de anorexia ${ }^{(1,}$ 11,13,19).

Nossos resultados também sugerem que a amiodarona deve alterar diferentemente o funcionamento de órgãos e/ou sistemas entre os sexos, uma vez que as fêmeas tratadas apresentaram menor número de células no LBA do que os machos tratados, indicando menor ação pneumotóxica da amiodarona no sexo feminino e menor ganho de peso corpóreo, indicando maior ação tóxica da droga sobre o metabolismo do organismo nesse sexo.

Em resumo, os resultados deste trabalho mostraram que, com $175 \mathrm{mg} /$ dia de amiodarona por quatro semanas, das três linhagens estudadas, a linhagem Wistar, embora não isogênica, é a que apresenta maior suscetibilidade pulmonar à amiodarona e que as linhagens SHR $e$ WKY não são adequadas para o estudo da toxicidade pulmonar induzida pela droga. Além disso, a amiodarona tem maior efeito sobre os pulmões em machos e sobre o metabolismo do organismo em fêmeas, o que limita a utilização de animais do sexo feminino em experimentos sobre a pneumonite induzida por amiodarona.

\section{REFERÊNCIAS}

1. Singh BN. Amiodarone: historical development and pharmacological profile. Am Heart J 1983;106:788-97.

2. Mason JW. Amiodarone. N Engl J Med 1987;316:455-66.

3. Reasor MJ, Kacew S. Amiodarone pulmonary toxicity: morphologic and biochemical features. Proc Soc Exp Biol Med 1991;196:1-7.

4. McGovern B, Garan H, Kelly E, Ruskin JN. Adverse reactions during treatment with amiodarone hydrochloride. Br Med J 1983;287:17580.

5. Fogoros RN, Anderson KL, Winkle RA, Swerdlow CD, Mason JW. Amiodarone: clinical efficacy and toxicity in 96 patients with recurrent, drug-refractory arrythmias. Circulation 1983;68:88-94.

6. Martin WJ II, Rosenow EC. Amiodarone pulmonary toxicity. Recognition and pathogenesis (part I). Chest 1988;68:88-94.

7. Martin WJ II, Rosenow EC. Amiodarone pulmonary toxicity. Recognition and pathogenesis (part II). Chest 1988;93:1242-8.

8. Rakita L, Sobol SM, Mostow N, Urobel T. Amiodarone pulmonary toxicity. Am Heart J 1983;106:906-14.

9. Terra Filho M, Meneghetti JC, Cukier A, Teixeira LR, Soares Júnior J, Camargo EE, Vargas FS. Gallium-67 lung imaging and pulmonary clearance of 99m Tc-DTPA aerosol in patients with amiodarone pneumonitis. Braz J Med Biol Res 1996;29:1467-71.

10. Costa Jussá FR, Corrin B, Jacobs JM. Amiodarone lung toxicity: a human and experimental study. J Pathol 1984;143:73-9.

11. Reasor MJ, Ogle CL, Walker ER, Kacew S. Amiodarone-induced phospholipidosis in rat alveolar macrophages. Am Rev Respir Dis 1988; 137:510-8.

12. Wilson BD, Clarkson CE, Lippmann ML. Amiodarone-induced pulmonary inflammation. Correlation with drug dose and lung levels of drug, metabolite, and phospholipid. Am Rev Respir Dis 1991;143:1110-4.

13. Wilson BD, Lippmann ML. Pulmonary accumulation of amiodarone and N-desethylamiodarone. Relationship to the development of pulmonary toxicity. Am Rev Respir Dis 1990;141:1553-8.

14. Nicodelis MAL, Carvalho CRR, Saldiva PHN, Santos SJ, Tavares JGN. Lesões pulmonares decorrentes do uso de amiodarona em ratos: relação entre achados histopatológicos e dosagem tecidual de droga. J Pneumol 1984;10(Supl):205
15. Antonini JM, Reasor MJ. Accumulation of amiodarone and desethylamiodarone by rat alveolar macrophages in cell culture. Biochem Pharmacol 1991;42(Suppl):S151-S6.

16. Liu FLW, Cohen RD, Downar E, Butany JW, Edelson JD, Rebuck AS. Amiodarone pulmonary toxicity: functional and ultrastructural evolution. Thorax 1986;41:100-5.

17. Martin WJ II, Osborn MJ, Douglas WW. Amiodarone pulmonary toxicity. Assessment by bronchoalveolar lavage. Chest 1985;88:630-1.

18. Israel-Biet D, Venet A, Caubarrere I, Bonan G, Danel C, Chretien J, Hance AJ. Bronchoalveolar lavage in amiodarone pneumonitis. Cellular abnormalities and their relevance to pathogenesis. Chest 1987; 91:214-21.

19. Wilson BD, Jaworski AJ, Donner ME, Lippmann ML. Amiodaroneinduced pulmonary toxicity in the rat. Lung 1989;167:301-11.

20. Akoun GM, Cadranel JL, Blanchette G, Milleron BJ, Mayaud CM. Bronchoalveolar lavage cell data in amiodarone-associated pneumonitis. Evaluation in 22 patients. Chest 1991;99:1177-82.

21. Ohar JA, Jackson F, Dettenmeier PA, Bedrossian CW, Tricomi SM, Evans RG. Bronchoalveolar lavage cell count and differential are not reliable indicators of amiodarone-induced pneumonitis. Chest 1992; 102:999-1004

22. Coudert B, Bailly F, Lombard JN, Andre F, Camus P. Amiodarone pneumonitis. Bronchoalveolar lavage findings in 15 patients and review of the literature. Chest 1992;102:1005-12.

23. Nagata N, Suematsu R, Yoshii C, Miyazaki H, Sueishi K, Kido M. Characterization of amiodarone pneumonitis as related to inflammatory cells and surfactant apoprotein. Chest 1997;112:1068-74.

24. Carvalho CRR, Kairalla RA, Capelozzi VL, Amato MPB, Saldiva PHN. Chronic amiodarone ingestion induces pulmonary toxicity in rats. Braz J Med Biol Res 1996;29:779-91.

25. Spiegel MR. Estatística. 2a ed. São Paulo: McGraw-Hill, 1985.

26. Martin WJ II, Howard DM. Amiodarone-induced lung toxicity. In vitro evidence for the direct toxicity of the drug. Am J Pathol 1985;120: 344-50.

27. Bargout R, Jankov A, Dinger E, Wang R, Komodromos T, Sunga OI, et al. Amiodarone induces apoptosis of human and rat alveolar epithelial cells in vitro. Am J Physiol Lung Cell Mol Physiol 2000;278: 103944.

28. Bolt MW, Card JW, Racz WJ, Brien JF, Massey TE. Disruption of mitochondrial function and cellular ATP levels by amiodarone and Ndesethylamiodarone in initiation of amiodarone-induced pulmonary cytotoxicity. J Pharmacol Exp Ther 2001;298:1280-9.

29. Akoun GM, Gauthier-Rahman S, Milleron BJ, Perrot JY, Mayaud CM. Amiodarone-induced hypersensitivity pneumonitis. Evidence of an immunological cell-mediated mechanism. Chest 1984;85:133-5.

30. Manicardi V, Bernini G, Bossini P. Low-dose amiodarone-induced pneumonitis: evidence of an immunological pathogenetic mechanism. Am J Med 1989;86:134-5.

31. Karpel JP, Mitsudo S, Norin AL. Natural killer cell activity in a rat model of amiodarone-induced interstitial lung disease. Chest 1991; 99:230-4

32. Vereckei A, Blazovics A, Gyorgy I, Feher E, Forth M. The role of free radicals in the pathogenesis of amiodarone toxicity. J Cardiovasc Electrophysiol 1993;161:77.

33. Okamoto K, Aoki K. Development of a strain of spontaneously hypertensive rats. Jpn Circ J 1963;27:282-93.

34. Queluz THAT. Mediação da imunopneumopatia aguda induzida por anticorpo antimembrana basal [tese de livre-docência]. Botucatu/SP: Faculdade de Medicina de Botucatu - Universidade Estadual Paulista, 1996. 